\title{
10 years of surveillance of human tularaemia in France
}

A Mailles (a.mailles@invs.sante.fr)'1, V Vaillant ${ }^{1}$

1. Foodborne and zoonotic diseases unit, French Institute for Public Health Surveillance, Saint-Maurice, France

Citation style for this article:

Mailles A, Vaillant V. 10 years of surveillance of human tularaemia in France. Euro Surveill. 2014;19(45):pii=20956. Available online: http://www.eurosurveillance. org/ViewArticle. aspx?Articleld=20956

Article submitted on 19 July 2013 / published on 13 November 2014

Tularaemia has been mandatorily notifiable in France since October 2002. The surveillance aims to detect early any infection possibly due to bioterrorism and to follow up disease trends. We report the results of national surveillance from 2002 to 2012. A case is defined as a patient with clinical presentation suggestive of tularaemia and biological confirmation of infection or an epidemiological link with a biologically confirmed case. Clinical, biological and epidemiological data are collected using a standardised notification form. From 2002 to 2012, 433 cases were notified, with a median age of 49 years (range 2 to 95 years) and a male-female sex ratio of 1.8. Most frequent clinical presentations were glandular tularaemia $(n=200$; $46 \%)$ and ulceroglandular tularaemia ( $n=113 ; 26 \%)$. Most frequent at-risk exposures were handling hares $(n=179 ; 41 \%)$ and outdoor leisure exposure to dust aerosols $(n=217 ; 50 \%)$. Tick bites were reported by 82 patients (19\%). Ten clusters (39 cases) were detected over the 10-year period, as well as a national outbreak during winter $2007 / 2008$. The tularaemia surveillance system is able to detect small clusters as well as major outbreaks. Surveillance data show exposure to dust aerosols during outdoor leisure activities to be a major source of contamination in France.

\section{Introduction}

Tularaemia is a disease caused by the bacterium Francisella tularensis, presenting with various clinical patterns. Infection due to $F$. tularensis subspecies holarctica encountered in Europe is usually relatively mild and less severe than the infection due to $F$. tularensis subspecies tularensis present in North America [1]. The clinical presentation is directly related to the route of infection, with local symptoms at the bacterium's point of entry. The most frequent presentation is an ulcer following the inoculation of the germ, associated with local adenopathy, or an isolated increased lymph node when the inoculation lesion goes unnoticed. In case of inhalation of the bacterium, pneumonia can occur with increased lymph nodes in the mediastina. Oropharyngeal tularaemia associated with swollen ear, nose and throat lymph nodes develops after the ingestion of the bacterium, and oculoglandular tularaemia when eyelids and other periorbital structures are infected, usually through aerosols or contact with fingers carrying the bacterium.

A wide range of animals, encompassing arthropods, birds, rodents, lagomorphs, carnivores and ruminants, can carry Francisella, but a definitive reservoir has not been identified [2]. It is likely that different epidemiological cycles exist in different environmental settings, suggesting that the primary reservoir may vary between cycles [3]. Not all animals play a significant role in the transmission of the bacterium to humans. In France, the disease has long been known to occur in people who skin hares, and has sometimes been called hunters' wives' disease $[4,5]$.

F. tularensis subspecies tularensis is considered worldwide to be a potentially weaponisable bacterium, and tularaemia fulfils the criteria for surveillance in the community in the event of deliberate release [6]. Epidemiological surveillance of human tularaemia was implemented in France in October 2002 as part of the national preparedness plan against bioterrorism. The surveillance is carried out by mandatory notification and by the analysis of strains and biological samples from patients by the national reference centre for $F$. tularensis (University Hospital of Grenoble, France). Besides detection of cases due to deliberate release of Francisella, the surveillance provides a precise description of cases diagnosed in France in a natural non-bioterrorist context. The purpose of this article is to present the results of national surveillance from 1 October 2002 to 31 December 2012.

\section{Methods}

In France, attending physicians and microbiologists must notify all cases of tularaemia to the regional health agencies using the standardised notification form. A case of tularaemia is defined as a patient presenting with clinical signs and symptoms suggestive of tularaemia; for a confirmed case, a positive PCR or the isolation of $F$. tularensis in a biological sample, or a seroconversion or four-fold increase of serological titre demonstrated on two samples taken with a minimum interval of two weeks; and for a probable case, a single elevated serological titre [7]. 


\section{FIGURE 1}

Classification of cases according to the most likely source or circumstance of infection, tularaemia cases notified in France, 2002-2012 $(\mathrm{n}=433)$

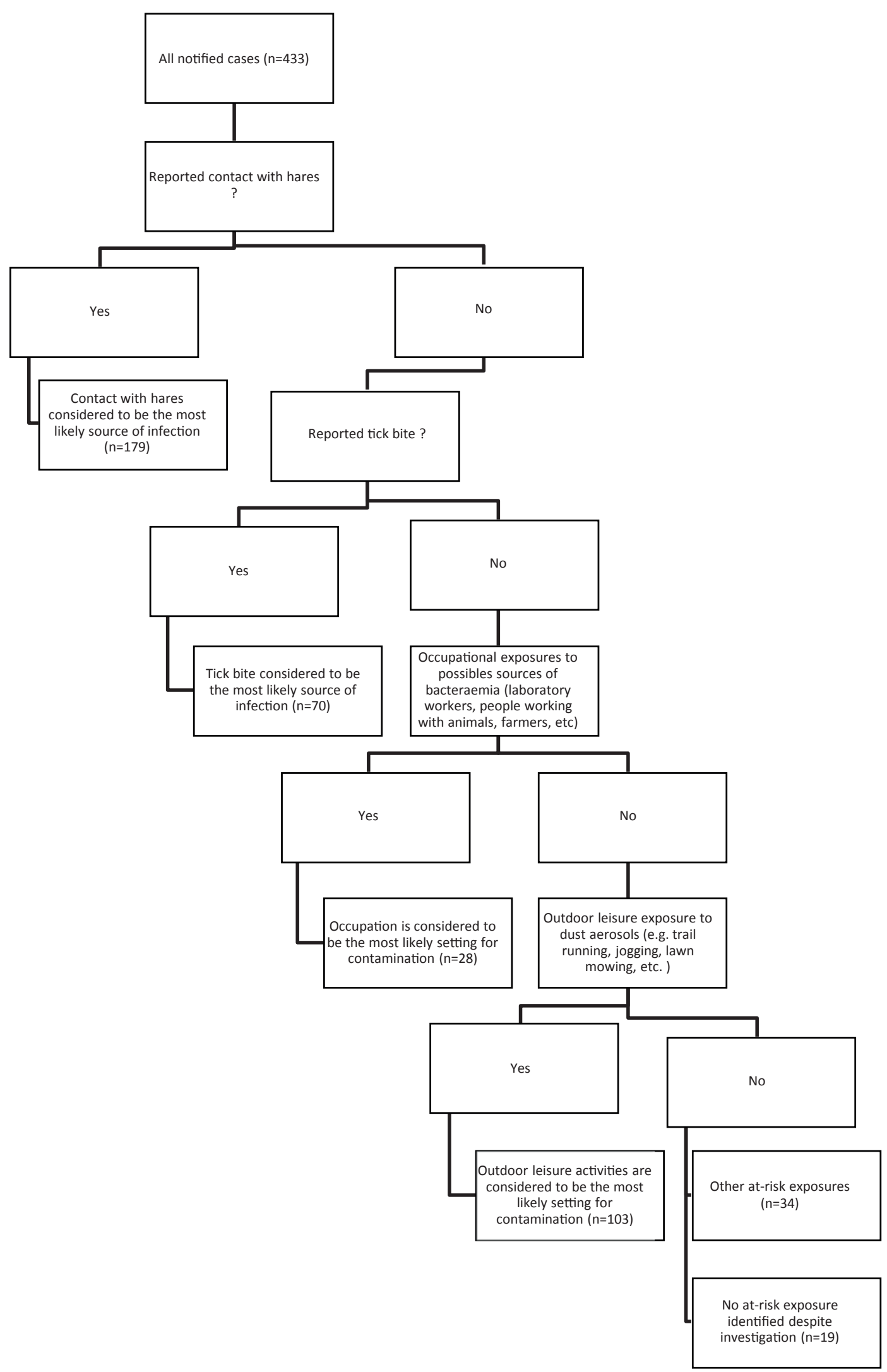




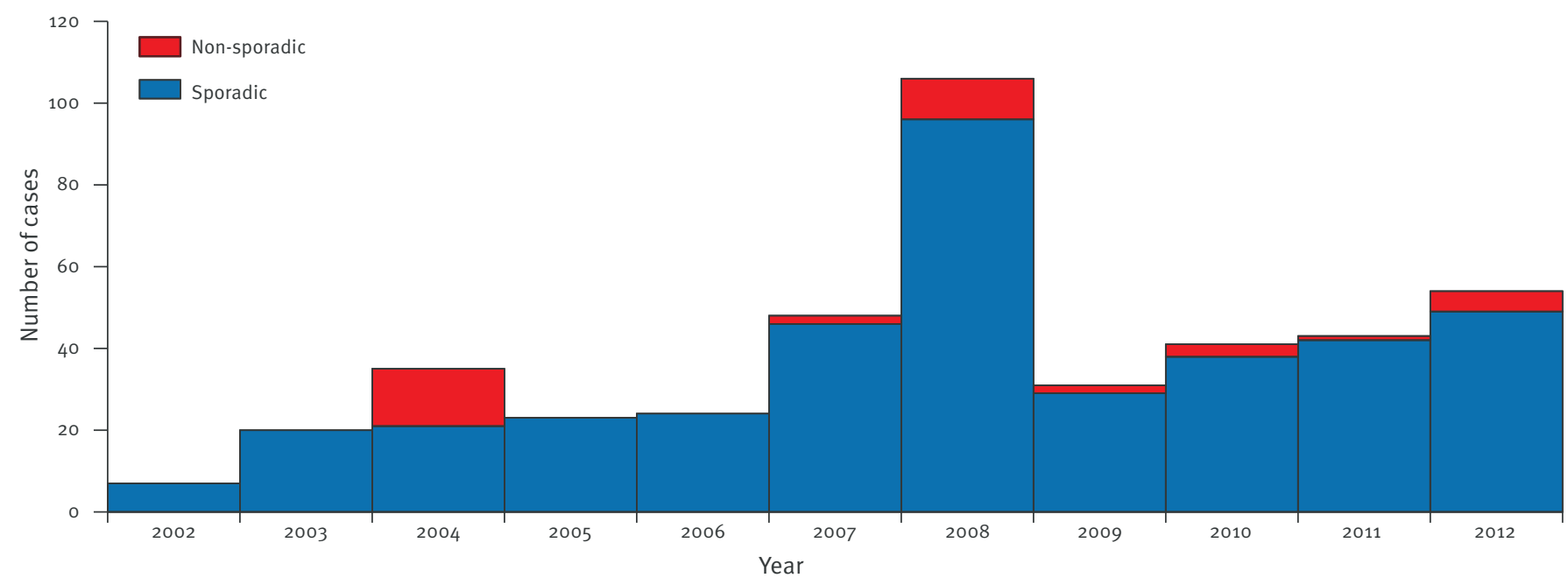

The notification form used for the surveillance encompasses clinical details, diagnosis features and at-risk exposures during the month before symptom onset. Clinical presentations are determined according to reported symptoms [8]. If no at-risk exposure is mentioned on the form, a trawling questionnaire is completed with the attending physician and the patient to rule out a possible non-natural contamination. When the diagnosis is obtained by the identification of a bacterial strain, the subspecies is determined by the national reference laboratory by PCR amplification and sequencing of the $16 \mathrm{~S}$ rRNA gene and the intergenic spacer region [9].

We attempted to attribute a most likely origin of contamination to each of the notified cases. We defined as at-risk exposures tick and mosquito bites received in Europe, direct contact with animals (including hares, rodents, wild rabbits, ruminants and crayfish), occupational exposure to animals or to an environment possibly contaminated by animals, outdoor activity exposure to dust or soil aerosols in areas where reservoir animals are present. More specifically in France, the handling, skinning or evisceration of hares have been known for years as a frequent cause of contamination [4]. By contrast, this exposure is rare in the general population, and rarer than tick bites, occupational exposure or outdoor activities. If a patient reported only one at-risk exposure, we attributed her or his most likely origin of contamination to this exposure. For patients reporting several at-risk exposures as defined above, we considered that the probability of an at-risk exposure being the source of contamination was inversely proportional to its frequency in the general population. For patients with several at-risk exposures, we attributed the most likely origin of contamination according to the following scheme (Figure 1):
- any patient infected with $F$. tularensis who reported direct contact with hares during the exposure period would have been infected through this exposure;

- a reported tick bite during the exposure period would be the contamination route of any patient unless the patient also reported direct contact with hares;

- an at-risk occupation during the exposure period would be the circumstance of contamination unless the patient also reported a direct contact with hares or a tick bite;

- leisure activities resulting in exposure to aerosols or dust in the forest during the at-risk period would be the circumstance of contamination unless the patient reported direct contact with hares, or a tick bite or an occupational exposure.

In the surveillance system, clusters of tularaemia cases are defined as more than one case reported in a single household or two or more cases in the same social circle, or as three or more cases in the same district within a 30-day period. Districts are administrative geographical areas, of which France has more than 100, including overseas territories, with populations ranging from 77,000 inhabitants to 2.5 million. All clusters are investigated using the trawling questionnaire.

All variables included in the notification form were computed using Voozanoo (EpiConcept, Paris, France) and analysed with Stata 11 (Stata Corporation, College Station, Texas, USA). Variables were compared using Pearson's chi-squared test or Student's t-test.

Surveillance data collection has been approved by the national ethics committee (CNIL), according to the French regulation on medical confidentiality. 


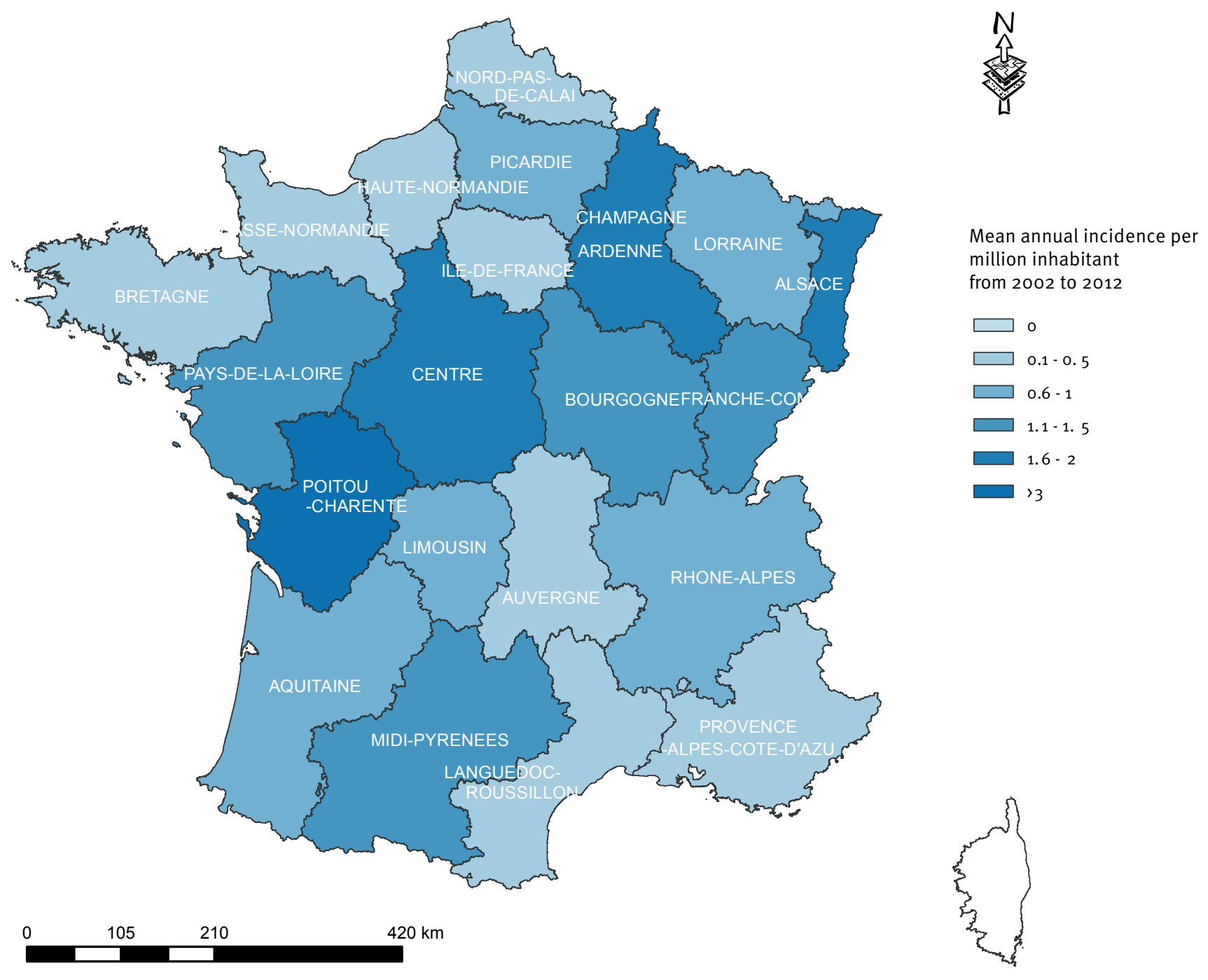

\section{Results}

Demographic data and seasonality

From 1 October 2002 to 31 December 2012, 433 cases of tularaemia were identified in France, making an annual mean incidence of 0.07 cases per 100,000 inhabitants (range 0.01-0.16). Of these, 395 (91\%) were sporadic cases and $39(9 \%)$ were notified as part of 10 clusters (see below) (Figure 2).

The global trend in the number of sporadic cases suggests a progressive increase in the number of notifications since surveillance began, except during winter $2007 / 2008$, when a short sudden peak of cases was recorded (Figure 2). The peak of cases during winter $2007 / 2008$ occurred simultaneously with an outbreak of tularaemia in hares and has been described elsewhere [10].
More cases had their onset of symptoms during autumn (September/October/November; $n=135 ; 31 \%$ ) and winter (December/January/February; $n=123 ; 28 \%$ ).

Cases were notified in all French regions except Corsica (Figure 3). The highest incidences each year were recorded in Poitou-Charentes (mean 0.32/year/100,000 inhabitants), and Alsace (mean 0.17/year/100,000).

The male-female sex ratio was 1.8 , and the mean age of cases was 49 years ( $S D=17$, range 2 to 95 years).

\section{Clinical presentation}

The most frequent clinical presentations were glandular $(n=200 ; 46 \%)$ and ulceroglandular tularaemia $(n=113 ; 26 \%)$. Typhoidal tularaemia $(n=45,10 \%)$, pneumonic $(n=42 ; 10 \%)$, oropharyngeal $(n=25 ; 6 \%)$ 


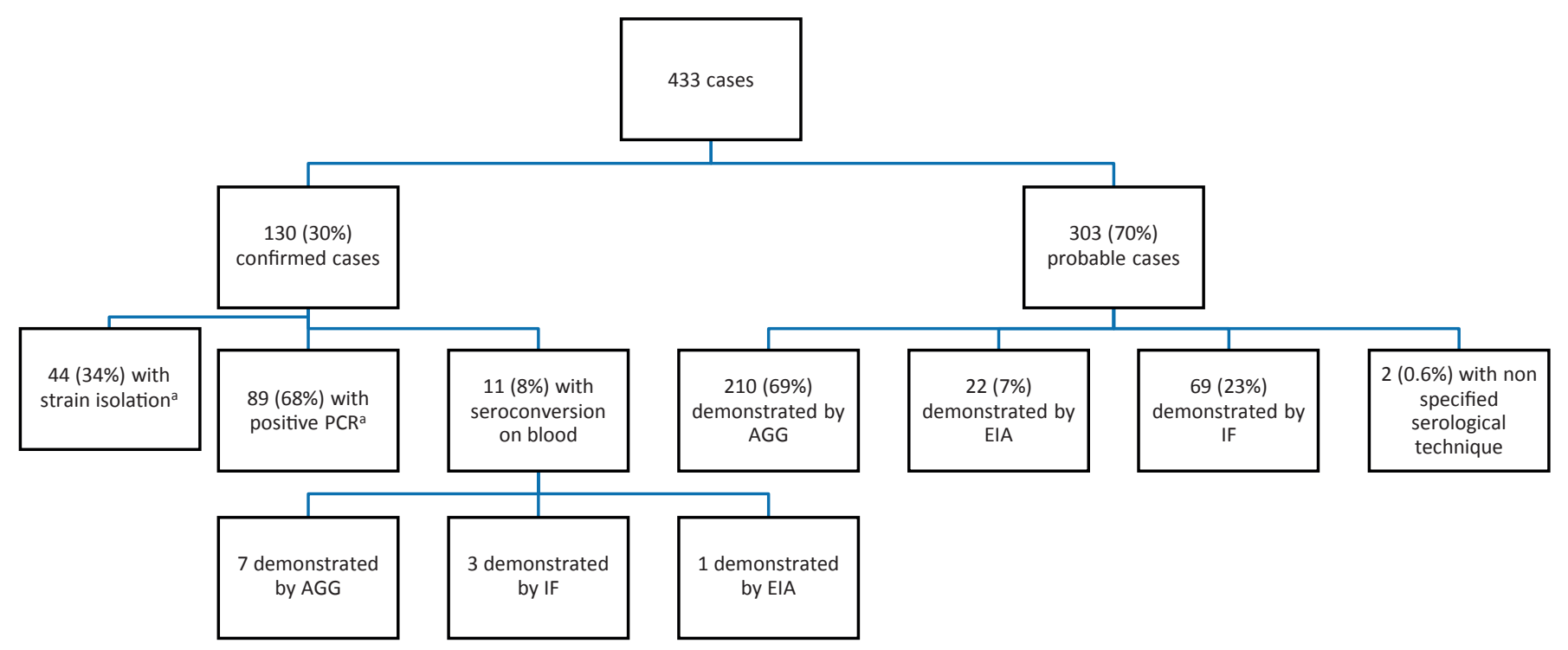

${ }^{a} 14$ cases had both a positive PCR and Francisella strain isolation

AGG: agglutination test; EIA: enzyme immunoassay; IF: immunofluorescence

and oculoglandular tularaemia $(n=8 ; 2 \%)$ were less common. Information about the localisation of the lymphadenopathy was available for 210 of 313 (67\%) patients presenting with glandular or ulceroglandular tularaemia. The adenopathy concerned armpit lymph nodes (LN) in 118 of 210 cases (56\%), inguinal LN in 56 (27\%), LN of the ear, nose and throat (ENT) area in 26 (12\%), epicondylar LN in $26(12 \%)$, mediastinal LN in 9 (4\%) and popliteal LN in 5 (2\%).

During the 10 years of surveillance, three patients with neurological presentations were notified. The first was a 66 year-old man who presented with encephalitis and a positive blood culture demonstrating Francisella. He had eaten a terrine made from hare meat a few days before the onset of disease; the remains of the terrine were found to be positive for Francisella on PCR. The second patient, a man aged 48 years, was admitted to an intensive care unit (ICU) with sudden brainstem encephalitis encompassing tetraplegia. Serology demonstrated a seroconversion for Francisella during his hospital stay. No other infectious agent that could be responsible for brainstem encephalitis was diagnosed. The patient had been bitten by a tick a few days before illness onset. The third patient was a man in his sixties with a history of pancreatic cancer and diabetes. He presented with pneumonia and encephalitis on admission, and a strain of Francisella was isolated from a cerebrospinal fluid (CSF) sample.

Other infrequent presentations were erythema nodosum in three patients, and a lobar pneumonia following a near-drowning in a patient who demonstrated a positive blood culture a few days after the drowning.
A total of 188 (43\%) patients required hospitalisation. At the time of notification, the evolution was considered favourable for 211 cases (49\%), the disease was still ongoing for 200 (46\%), 20 presented with complications, and two patients had died. The complications were $\mathrm{LN}$ abscess in 15 cases (75\%), pulmonary abscess in one case, palpebral abscess in one case, erysipelas in one case, parotiditis in one case and labyrinthitis in one case. The two deaths occurred in two male patients aged in their eighties and nineties. The first patient had a chronic history of severe cardiac arrhythmia and presented with pneumonic tularaemia with positive blood culture. The second patient presented at first with fever and had a positive blood culture of an unidentified bacterium initially assumed to be due to laboratory contamination. By the time the isolated bacterium was properly identified as Francisella, the patient had developed pneumonia and later presented with acute respiratory distress syndrome and septic shock.

\section{Laboratory diagnosis}

Of the 433 tularaemia cases, 130 (30\%) were confirmed cases and $303(70 \%)$ were probable cases (Figure 3 ). Of the 130 confirmed cases, 30 (23\%) cases were diagnosed by isolation of a strain of Francisella, 75 (58\%) by PCR, 14 (11\%) by both isolation and PCR, and 11 (8\%) by seroconversion. The 44 strains isolated all belonged to $F$. tularensis subspecies holarctica and were isolated from blood $(n=19 ; 43 \%)$, abscess puncture $(n=4 ; 9 \%)$, LN biopsy $(n=8 ; 18 \%)$, skin biopsy $(n=8 ; 18 \%)$, conjunctival swab $(n=2 ; 5 \%)$, CSF $(n=1 ; 2 \%)$ and undetermined samples $(n=2 ; 5 \%)$. The 89 positive PCR were obtained from $L N(n=67 ; 75 \%)$, skin biopsy $(n=7 ; 8 \%)$, 
TABLE 1

At-risk occupations of tularaemia cases notified in France, 2002-2012 (n=79)

\begin{tabular}{|l|c|}
\hline At-risk occupation & Number (\%) \\
\hline Farmer/cattle breeder & $38(51)$ \\
\hline Forest worker & $12(16)$ \\
\hline Butcher/kitchen worker & $7(9)$ \\
\hline Laboratory worker & $4(5)$ \\
\hline Veterinarian/veterinary nurse & $4(5)$ \\
\hline Fruits and vegetable producer & $4(5)$ \\
\hline Landscaper & $3(4)$ \\
\hline Vineyard worker & $3(4)$ \\
\hline Petshop worker & $1(1)$ \\
\hline Rendering plant worker & $1(1)$ \\
\hline Horse riding teacher & $1(1)$ \\
\hline Farm machine dealer & $1(1)$ \\
\hline Total & $\mathbf{7 9 ( 1 0 0 )}$ \\
\hline
\end{tabular}

pharyngeal swabs $(n=5 ; 6 \%)$, whole blood sample $(n=2 ; 2 \%)$, abscess pus $(n=2 ; 2 \%)$, serum sample $(n=1$; $1 \%)$, conjunctival swab $(n=1 ; 1 \%)$ and undetermined samples $(n=4 ; 4 \%)$.The 303 probable cases were diagnosed by a single elevated titre in serology using various methods (Figure 4).

\section{At-risk exposures reported by cases}

79 (18\%) patients reported occupational activities exposing to animals or an environment possibly contaminated by animals (Table 1). A total of 82 (19\%) patients reported tick bites before onset of symptoms: of these, $15(18 \%)$ lived in Alsace and 7 ( $8 \%)$ in Lorraine, both regions are located along the German-French border. Non-occupational direct contacts with one or more different animals were reported by 311 (72\%) patients. The most frequent animals reported were hares $(n=179$; $41 \%)$ and rodents $(n=42 ; 10 \%)$ (Table 2$)$.

The most frequent at-risk exposures reported by patients were outdoor leisure exposure to dust aerosols $(n=217,50 \%)$, such as gardening, jogging or biking in the forest.

\section{Most likely source of contamination}

We determined the most likely source of contamination for the cases as described in the methods section: hare handling for 179 (41\%) patients, and tick bite for $70(16 \%)$. For other patients, the most likely circumstance of contamination was an at-risk occupation for $28(6 \%)$ and outdoor leisure activities for 103 (24\%). 34 ( $8 \%$ ) patients had various other at-risk exposures and 19 (4\%) did not report any at-risk exposures.

The sex and age distribution did not differ significantly between the four main exposure groups (hares, ticks, occupational and outdoor leisure). Systemic presentations (pneumonic tularaemia and typhoidal tularaemia)
TABLE 2

At-risk exposures reported by tularaemia cases notified in France, 2002-2012 (N=433)

\begin{tabular}{|c|c|}
\hline At-risk exposures & Number (\%) \\
\hline Occupational & 79 (18) \\
\hline $\begin{array}{l}\text { Non-occupational direct contact with } \\
\text { animals }\end{array}$ & $311(72)$ \\
\hline \multicolumn{2}{|l|}{ Game animals } \\
\hline Hares & $179(41)$ \\
\hline Boars & $8(2)$ \\
\hline Roe deer & $8(2)$ \\
\hline \multicolumn{2}{|l|}{ Breeding animals } \\
\hline Rabbits & $18(4)$ \\
\hline Cattle & $2(0.5)$ \\
\hline Goats & $2(0.5)$ \\
\hline Sheep & $3(0.7)$ \\
\hline Poultry & $8(2)$ \\
\hline \multicolumn{2}{|l|}{ Pet animals } \\
\hline Dogs & $16(4)$ \\
\hline Cats & $13(3)$ \\
\hline Horses & $5(1)$ \\
\hline \multicolumn{2}{|l|}{ Wildlife excluding game animals } \\
\hline Rodents (excluding pet rodents) & $42(10)$ \\
\hline Stone martens & $1(0.2)$ \\
\hline Foxes & $1(0.2)$ \\
\hline Non-specified animal & $49(11)$ \\
\hline Outdoor leisure activities & $217(50)$ \\
\hline Hunting & $52(12)$ \\
\hline Gardening & $59(14)$ \\
\hline Sport & $51(12)$ \\
\hline House work/rehabilitation & $11(3)$ \\
\hline Tick bites & $82(19)$ \\
\hline Mosquitoes/tabanids bites & $29(7)$ \\
\hline Total at-risk exposures & $433(100)$ \\
\hline
\end{tabular}

A case could report several at-risk exposures.

were significantly more frequent in patients exposed through outdoor leisure $(n=35 ; 34 \%)$ or occupation $(n=8 ; 29 \%)$ than through tick bites $(n=10 ; 14 \%)$ or hares $(n=19 ; 11 \%)(p<0.05)$ (Table 3). By contrast, glandular and ulceroglandular tularaemia were significantly more frequent in patients with tick bites as the most likely source of infection $(n=60 ; 86 \%)$ or hares $(n=185 ; 81 \%)$ than in patients presumably contaminated through outdoors leisure $(n=56 ; 57 \%)$ or occupational activities $(n=17 ; 61 \%)$ pro.05).

Monthly distribution of cases by most probable source of infection is presented in Figure 5. Contamination most likely due to hares occurred during the legal hunting period (from September to February), contamination most likely related to tick bites occurred in spring and summer. By contrast, contamination most likely 
Distribution of clinical presentations, by most likely source of contamination, tularaemia cases notified in France, $2002-2012(n=380)$

\begin{tabular}{|l|c|c|c|c|} 
& Hare handling & Tick bite & $\begin{array}{c}\text { At-risk } \\
\text { occupation }\end{array}$ & Outdoor leisure activities \\
\hline Glandular & $94(53 \%)$ & $33(47 \%)$ & $14(50 \%)$ & $35(34 \%)$ \\
\hline Ulceroglandular & $51(28 \%)$ & $27(39 \%)$ & $3(11 \%)$ & $24(23 \%)$ \\
\hline Typhoidal & $10(6 \%)$ & $6(9 \%)$ & $4(14 \%)$ & $16(16 \%)$ \\
\hline Pneumonic & $9(5 \%)$ & $4(6 \%)$ & $4(14 \%)$ & $19(18 \%)$ \\
\hline Oropharyngeal & $12(7 \%)$ & $0(0 \%)$ & $2(7 \%)$ & $6(6 \%)$ \\
\hline Occuloglandular & $3(2 \%)$ & $0(0 \%)$ & $1(4 \%)$ & $3(3 \%)$ \\
\hline Total & $\mathbf{1 7 9 ( 1 0 0 \% )}$ & $\mathbf{7 0 ( 1 0 0 \% )}$ & $\mathbf{2 8 ( 1 0 0 \% )}$ & $\mathbf{1 0 3 ( 1 0 0 \% )}$ \\
\hline
\end{tabular}

A case could report several at-risk exposures.

related to occupational or outdoor leisure activities occurred throughout the year.

Four patients were laboratory workers. Two of them worked in hospital laboratories and had handled biological samples of two other cases without taking appropriate precautions. The other two were working for local veterinary services and had carried out postmortem examinations on infected hares without the necessary protection. Twelve ( $3 \%$ ) cases were considered to be imported as they had spent the month before onset of illness in other countries where they reported at-risk exposures.

\section{Clusters}

From 2002 to 2012, 10 clusters were detected through the surveillance system: two were laboratory-acquired infections (see above), three were air-borne clusters, four were food-borne outbreaks and the origin of the last cluster is unknown.

Air-borne cluster of cases

A cluster involving 14 patients occurred among tourists staying in a rural cottage in western France in 2004 [11]. Six patients presented with pneumonia and eight with typhoidal tularaemia. The investigation concluded that there had been air-borne contamination through aerosols from a highly contaminated rural environment. A cluster of airborne tularaemia infections was notified in 2012 in two neighbours who had cleared the undergrowth together in a field on a rabbit-breeding farm. Both patients presented with pneumonia.

During the summer of 2008,10 French tourists were hiking in Spain along the pilgrim route to Santiago de Compostela. At this time, a major tularaemia outbreak occurred in this area of Castilla y Leon [12]. Eight of the tourists reported various non-specific symptoms at the end of their travel: fever $(n=5)$, malaise $(n=8)$, dyspnea $(n=2)$ and conjunctivitis $(n=1)$. They did not receive any treatment. Five were tested by serology after they returned in France and three were positive (the two who reported dyspnea and the one who reported conjunctivitis).

Food-borne clusters

Four food-borne clusters were identified in 2007, 2008, 2009 and 2012. Three of these occurred following the handling, skinning and culinary preparation of hares rather than hare consumption. They involved, respectively, a hunter and his wife, a hunter and his neighbour, and three members of one family. The fourth food-borne cluster involved seven people who prepared and ate a hare they had found dead in the countryside for a family lunch. All seven presented with massive oedema of tongue and pharyngitis a few hours after the shared meal. The hare had been prepared following a local recipe that used the uncooked liver and blood of the animal.

Cluster with undetermined origin of contamination A married couple were diagnosed with tularaemia by serology after returning from Italy in 2010. No at-risk exposure was retrieved from their interview and both presented with non-specific abdominal pain and digestive symptoms. Although their clinical presentation suggested food-borne contamination, it was not possible to determine the source of infection.

Diagnosis and notification delays

The median time from symptom onset to diagnosis was 24 days (range 1 to 254), and was 19 days from diagnosis to notification (range o to 470 days). However, these delays were shorter for cluster patients (respectively 11 days, $p=0.003$ from onset to diagnosis, and 20 days, $\mathrm{p}=0.25$ from diagnosis to notification).

\section{Discussion}

Tularaemia has been mandatorily notifiable in France for 10 years, and an increasing number of cases has been reported every year since then. It is likely that the increase is due to more systematic notifications rather than to an increasing incidence of the disease, and that 


\section{FIGURE 5}

Distribution of notified cases of tularaemia, by month of onset of symptoms, France, 2002-2012
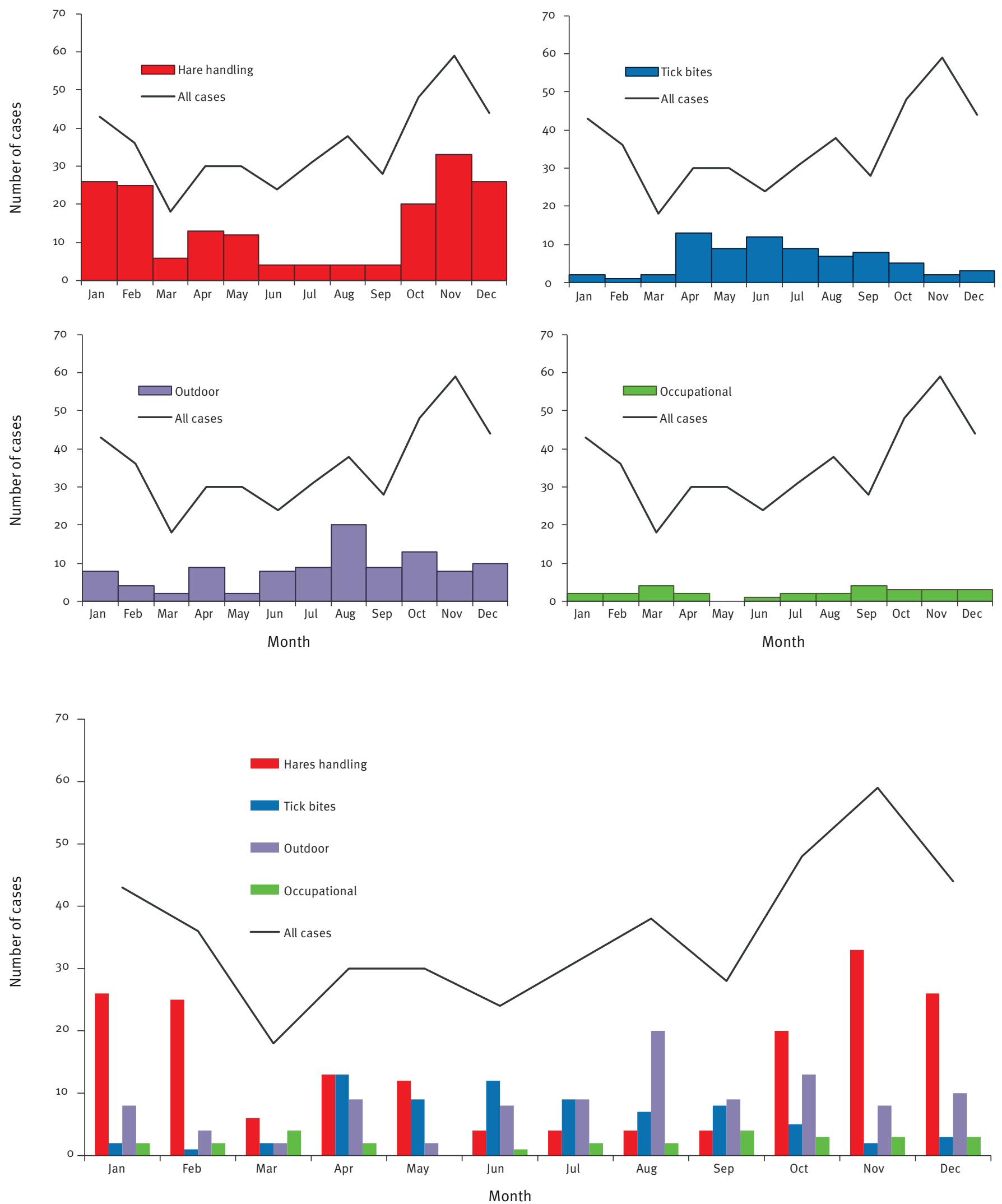
the numbers of reported cases will continue to increase in the next few years.

Tularaemia is notifiable at the European level with a standardised case definition [13]. The case definition used in France is more specific than the European case definition, as laboratory confirmation is required to notify cases, even when an epidemiological link is demonstrated. However, if a suspected case with only an epidemiological link to a case were to be notified, we would request that the suspected case be tested for tularaemia. We are therefore confident that we do not miss cases due to our case definition. Another difference is the classification of probable versus confirmed case. Because all cases are reported to ECDC, this difference does not result in a different interpretation of data at the national or European level.

In 2011, Europe's highest annual incidences were reported in Finland (7.6/100,000 inhabitants) and Sweden $(2.6 / 100,000)$ [14]. By contrast, the disease was rare in France in 2011 (0.07/100,000). The incidence in neighbouring countries the same year, such as Germany $(0.17 / 100,000)$ or Italy $(0.19 / 100,000)$, is higher than the national French incidence, although far lower than in Finland or Sweden. However, France's Alsace region, located along the German-French border, reported an incidence $(0.17 / 100,000)$ in 2011 comparable to the German incidence, suggesting common epidemiological patterns.

The low incidence reported in France suggests that the annual average of 40 cases notified underestimates the real number of cases. Some physicians probably do not know that the disease is notifiable because of its rarity. Moreover, because the clinical presentation may be non-specific, especially for typhoidal or pneumonic forms, some infections may not be diagnosed. Due to the absence of other independent sources of information about human tularaemia in France, the exhaustiveness of the surveillance system cannot be assessed.

The surveillance system identified 10 clusters of patients and a nationwide outbreak in 2007/2008. For all but one cluster, the investigation quickly ruled out the hypothesis of any intentional release of Francisella. During the winter outbreak of $2007 / 2008$, the most frequent at-risk exposure was direct contact with hares [10]. During the same period, the surveillance of tularaemia in hares displayed a concomitant increase in this species, suggesting a causal link between the outbreak among humans and among hares or a common environmental exposure, and therefore making the hypothesis of bioterrorism unlikely. The number of cases of tularaemia in France is likely underestimated. Despite this, the results reported here confirm that the human surveillance system is able to detect small clusters as well as large outbreaks and therefore plays its role in preparedness for and early detection of bioterrorism.
The median delays from onset of symptoms to diagnosis, and from diagnosis to notification are too long and are not compatible with the necessary early detection in case of bioterrorism. However, it should be noticed that tularaemia is a rare disease in France, possibly presenting with non-specific early symptoms. Due to the absence of $F$. tularensis subspecies tularensis in France, most cases present with mild clinical signs, probably resulting in an increased delay before the diagnosis is suggested. Moreover, in case of bioterrorism, we would expect to detect clustered cases with severe clinical presentation and an unusual geographical distribution (urban areas), even before those cases are diagnosed with tularaemia. However, these data give important clues for improvement of the surveillance system. Special attention will be given to shortening the timeframe for diagnosis and notification in the future, especially by raising clinician and microbiologist awareness for reporting the cases to the public health authorities.

The most frequently reported at-risk exposures among cases were outdoor leisure exposure to dust aerosols. This exposure is, however, very common in the general population. More interestingly, common at-risk exposures known as main routes of infection in other European countries were far less frequent in France: mosquito bites known as a major source of infection in Sweden [15], and contact with water animals such as crayfish responsible for a major outbreak in Spain [16]. These results suggest that an aquatic ecological/epidemiological cycle of Francisella might be of low epidemiological importance in France. A frequent at-risk exposure among patients was direct contact with hares. Hares are known to be a major reservoir of Francisella and a source of infection for humans in North America and several European countries [4,1719]. By contrast with outdoor activities, handling hares is a rare at-risk exposure in the general population but is frequent among tularaemia cases and can therefore be considered a likely cause of infection when reported. However, we may overestimate the proportion of cases attributable to hare handling since clinicians are more likely to investigate tularaemia in patients reporting hare handling than in other patients.

Tick bites were a frequent (19\%) but not major at-risk exposure among French cases, compared with outdoor leisure activities (50\%) or contact with hares (41\%). Most cases with tick bites lived close to the GermanFrench border in an area known to be the main focus in France for other tick-borne diseases such as tick-borne encephalitis or Lyme disease $[20,21]$. However, rare tick-borne tularaemia cases were identified throughout all French districts. It is also possible that cases reporting outdoors activity as their only at-risk exposure may also have been exposed to mosquito or tick bites that went unnoticed.

Our attempt to attribute a most likely source of infection based on the at-risk exposures reported by the 
cases demonstrated a significant association between the clinical presentation and the likely source of infection. Systemic presentations were associated with atrisk exposures suggesting air-borne infection whereas focalised clinical presentations were associated with atrisk exposures responsible for inoculation. Moreover, the presumed sources of infection were consistent with the timeline of onset of symptoms for all cases: cases presumed to be related to contact with hares occurred during the hunting season, those presumed to have resulted from tick bites occurred in spring and summer when ticks are most active, and cases associated with occupational exposure or outdoor leisure activities were recorded throughout the year.

Only two deaths were recorded during the 10 years of surveillance. There is no follow-up of the patients after the notification, we therefore cannot be sure that other patients did not experience later unfavourable outcomes. However, because only F. tularensis subspecies holarctica is present in France, a favourable outcome is expected in most patients. Indeed, the two patients with a fatal outcome had severe underlying diseases before their tularaemia infections, and these underlying conditions may have contributed to their death.

Three patients with severe neurological presentations were notified. Central nervous system (CNS) infections due to Francisella have been described infrequently in the literature and most published cases presented with meningitis rather than encephalitis [22-25]. All three cases reported to the surveillance system had encephalitis with serious brain involvement. Francisella could be isolated from CSF in only one patient with severe underlying immunosuppressive conditions. The absence of bacterium or antibodies in the CSF of the two other patients suggest a possible immune-mediated phenomenon rather than a direct invasion of CNS.

\section{Conclusion}

Mandatory notification of tularaemia implemented in France in $\mathbf{2 0 0 2}$ has demonstrated its value for the detection of clusters and outbreaks. It is very likely that the incidence is currently underestimated due to probable underdiagnosis and undernotification. Therefore, efforts should be made to increase clinician awareness of the disease and the available diagnosis tools. Currently, the main sources of infection in France are hares, outdoor activities and tick bites. Hunters should be advised to wear gloves to skin game, and people exposed to tick bites should be advised to take protective measures such as wearing long trousers for outdoors activities and to carefully examine themselves for ticks and to remove them rapidly.

\section{Authors' contributions}

$A M$ and VV coordinate the surveillance of tularaemia, including validation of notified cases and data, coordination of investigations when needed, and analyse of surveillance data. $A M$ and VV analysed the data presented in the manuscript.
$A M$ wrote the manuscript, $V V$ revised the manuscript and provided comments.

\section{Acknowledgements}

This work was funded by the French Institute for Public Health Surveillance (InVS).

The authors would like to thank all physicians, biologists, local public health workers and patients who contributed to the surveillance, the members of the SAGIR network and the bacterial zoonosis unit at the French food safety agency, who are in charge of tularaemia surveillance in wildlife, and the chief biologists at the national reference centre for Francisella tularensis, and their teams (from 2002 to 2005: Dr Vaissaire (Maisons-Alfort) and Dr Le Coustumier (Cahors); from 2006 to 2012: Professor Maurin (Grenoble) and Dr Pelloux (Grenoble), and since 2012: Professor La Scola (Marseille), Professor Maurin (Grenoble), Dr Pelloux (Grenoble), Dr Socolovitchi (Marseille)).

References

1. Ellis J, Oyston PC, Green M, Titball RW. Tularemia. Clin Microbiol Rev. 2002;15(4):631-46. http://dx.doi.org/10.1128/ CMR.15.4.631-646.2002

2. Tärnvik A, Priebe HS, Grunow R. Tularaemia in Europe: an epidemiological overview. Scand J Infect Dis. 2004;36(5):3505. http://dx.doi.org/10.1080/00365540410020442

3. Mörner T. The ecology of tularaemia. Rev Sci Tech. 1992;11(4):1123-30.

4. Vaissaire J, Mendy C, Le Doujet C, Le Coustumier A. [Tularemia. The disease and its epidemiology in France]. Med Mal Infect. 2005;35(5):273-80. French. http://dx.doi.org/10.1016/j. medmal.2005.03.005

5. Bernard L, Viguie. [Evolution of tularemia in France]. Rev Hyg Med Soc. 1953;1(4):329-35. French.

6. European Commission. 2003/534/EC: Commission Decision of 17 July 2003 amending Decision No 2119/98/EC of the European Parliament and of the Council and Decision $2000 / 96 / E C$ as regards communicable diseases listed in those decisions and amending Decision 2002/253/EC as regards the case definitions for communicable diseases (Text with EEA relevance) (notified under document number C(2003) 2301). Official Journal of the European Union. Luxembourg: Publications Office of the European Union. 23.07.2003:L184/35. Available from: http://eur-lex.europa.eu/ legal-content/EN/TXT/?uri=CELEX:32003D0534

7. Institut de veille sanitaire (InVS). Tularémie : définition de cas. Saint-Maurice: InVS. [Accessed 10 January 2014]. Available from: http://www.invs.sante.fr/Dossiersthematiques/Maladies-infectieuses/Zoonoses/Tularemie/ Comment-signaler-et-notifier-cette-maladie

8. Centers for Disease Control and Prevention (CDC). Tularemia: Signs \& symptoms. [Accessed 16 January 2014]. Available from: http://www.cdc.gov/tularemia/signssymptoms/index.html

9. Maurin M, Castan B, Roch N, Gestin B, Pelloux I, Mailles A et al. Real-time PCR for diagnosis of oculoglandular tularemia. Emerg Infect Dis. 2010;16(1):152-3. http://dx.doi.org/10.3201/ eid1601.090793

10. Mailles A, Madani N, Maurin M, Garin-Bastuji B, Vaillant V. [Unexpected increase of human and animal tularemia cases during winter 2007/2008 in France: Emergence or short-lasting episode?]. Med Mal Infect. 2010;40(5):279-84. French. http:// dx.doi.org/10.1016/j.medmal.2009.11.006

11. Barataud D, Siret V, Prat M, Ansart S, Le Coustumier A, Vaissaire J et al. Cas groupés de tularémie, Vendée, août 2004. [Grouped cases of tularaemia, Vendée, August 2004]. Bull Epid Hebdo. 2006;17:117-9. [Accessed 5 March 2013]. Available from: http://opac.invs.sante.fr/doc_num. php?explnum_id $=4907$

12. Martin C, Gallardo M, Mateos L, Vian E, Garcia M, Ramos J, et al. Outbreak of tularaemia in Castilla y León, Spain. Euro Surveill 2007;12(11):E071108.1.

13. European Commission. Commission implementing decision (2012/506/EU) of 8 August 2012 amending Decision 2002/253/ EC laying down case definitions for reporting communicable diseases to the Community network under Decision No 2119/98/EC of the European Parliament and of the Council. Official Journal of the European Union. Luxembourg: 
Publications Office of the European Union. 27.9.2012. Available from: http://eur-lex.europa.eu/LexUriServ/LexUriServ.do?uri= OJ:L:2012:262:0001:0057:EN:PDF

14. Anonymous. Tularemia. In: European Centre for Disease Prevention and Control. Annual Epidemiological Report 2011. Reporting on 2009 surveillance data and 2010 epidemic intelligence data. Stockholm: ECDC; 2011. P. 113-5. Available from: http://www.ecdc.europa.eu/en/publications/ Publications/1111_SUR_Annual_Epidemiological_Report_on Communicable_Diseases_in_Europe.pdf

15. Eliasson H, Lindbäck J, Nuorti JP, Arneborn M, Giesecke J, Tegnell A. The 2000 tularemia outbreak: a case-control study of risk factors in disease-endemic and emergent areas, Sweden. Emerg Infect Dis. 2002;8(9):956-60. http://dx.doi. org/10.3201/eido809.020051

16. Anda P, Segura del Pozo J, Díaz García JM, Escudero R, García Pe-a FJ, López Velasco MC, et al. Waterborne outbreak of tularemia associated with crayfish fishing. Emerg Infect Dis. 2001;7(3 Suppl):575-82. http://dx.doi.org/10.3201/ eido707.017740

17. Hauri AM, Hofstetter I, Seibold E, Kaysser P, Eckert J, Neubauer $\mathrm{H}$, et al. Investigating an airborne tularemia outbreak, Germany. Emerg Infect Dis. 2010;16(2):238-43. http://dx.doi. org/10.3201/eid1602.081727

18. Aldea-Mansilla C, Nebreda T, García de Cruz S, Dodero E, Escudero R, Anda P, et al.[Tularemia: a decade in the province of Soria (Spain)]. Enferm Infecc Microbiol Clin. 2010;28(1):21-6. Spanish. http://dx.doi.org/10.1016/j.eimc.2008.11.017

19. Gyuranecz M, Rigó K, Dán A, Földvári G, Makrai L, Dénes B, et al. Investigation of the ecology of Francisella tularensis during an inter-epizootic period. Vector Borne Zoonotic Dis. 2011 Aug;11(8):1031-5. http://dx.doi.org/10.1089/vbz.2010.0091

20. Thorin C, Rigaud E, Capek I, André-Fontaine G, Oster B, Gastinger G, Abadia G. [Seroprevalence of Lyme Borreliosis and tick-borne encephalitis in workers at risk, in eastern France]. Med Mal Infect. 2008 Oct;38(10):533-42. http://dx.doi. org/10.1016/j.medmal.2008.06.008

21. Vandenesch A, Turbelin C, Couturier E, Arena C, Jaulhac B, Ferquel E, Choumet V, Saugeon C, Coffinieres E, Blanchon T, Vaillant V, Hanslik T. Incidence and hospitalisation rates of Lyme borreliosis, France, 2004 to 2012. Euro Surveill 2014 Aug 28;19(34). pii: 20883.

22. Contentin L, Soret J, Zamfir O, Gontier O, Lherm T, Hamrouni M, et al. Francisella tularensis meningitis. Med Mal Infect. 2011;41(10):556-8. http://dx.doi.org/10.1016/j. medmal.2011.07.004

23. Alfes JC, Ayers LW. Acute bacterial meningitis caused by Francisella tularensis. Pediatr Infect Dis J. 1990;9(4):300-1. http://dx.doi.org/10.1097/00006454-199004000-00019

24. Hutton JP, Everett ED. Response of tularemic meningitis to antimicrobial therapy. South Med J. 1985;78(2):189-90. http:// dx.doi.org/10.1097/00007611-198502000-00016

25. Hofinger DM, Cardona L, Mertz GJ, Davis LE. Tularemic meningitis in the United States. Arch Neurol. 2009;66(4):523-7. http://dx.doi.org/10.1001/archneurol.2009.14 